enterovirus 71 infection. N Engl J Med March 22, 2007;356:1226-1234). (Reprints: Dr Chang, Department of Pediatrics, National Taiwan University Hospital, College of Medicine, National Taiwan University, No 7, Chung-Shan South Rd, Taipei, Taiwan).

COMMENT. Enterovirus, an RNA nonpoliovirus, causes significant and frequent illnesses in infants and children. Clinical manifestations of EV17 are protean and include hand-foot-and mouth disease, brainstem encephalitis and polio-like paralysis. Isolation of the virus in cell culture is the standard diagnostic method, and stool and throat specimens produce the highest yield (AAP Redbook, 27 $7^{\text {th }}$ ed, 2006). The above report shows that neurologic sequelae are frequent, especially in patients with cardiopulmonary failure. Behavior and learning problems present later on attending school, and $13 \%$ are diagnosed and treated for ADHD.

\title{
OPSOCLONUS-MYOCLONUS AND STREPTOCOCCAL INFECTION
}

A 9-year-old Nepalese boy living in the UK presented with opsoclonus-myoclonus syndrome associated with group A streptococcal infection, and is reported from St Mary's Hospital, London; and University of Southampton, UK. The onset was acute with headache, random eye movements, vomiting, dizziness, photophobia, and jerking of all four limbs. On examination, he had rapid, chaotic eye movements, myoclonus affecting limbs and head, and ataxia. He was empirically treated with ceftriaxone, acyclovir and azithromycin. Neuroblastoma was excluded. Bacterial cultures of blood, urine, and throat swab were negative. CSF contained 18 lymphocytes $/ \mathrm{ml}$ and 0 neurophils, $0.26 \mathrm{~g} / \mathrm{L}$ protein, and normal glucose and lactate. CSF culture, pcr, and viral antibodies were negative. Serum was negative for viral antibodies. Antistreptolysin 0 was 640 units $/ \mathrm{ml}$ initially and 1600 units $/ \mathrm{ml}$ at 4 months follow-up. Anti-DNase B was $2880 \mathrm{units} / \mathrm{ml}$ on day $1,1920 \mathrm{u} / \mathrm{ml}$ on day 2, and 360 $\mathrm{u} / \mathrm{ml}$ on day 22. After 2 weeks his eye movements, myoclonus and ataxia had improved. After 4 months he had recovered completely without sequelae. (Jones, CE, Smyth DPL, Faust SN. Opsoclonus-myoclonus syndrome associated with group A streptococcal infection. Pediatr Infect Dis J April 2007;26:358-359). (Respond: Dr Saul N Faust, Wellcome Trust Clinical Research Facility, University of Southampton, Mailpoint 218, C Level, West Wing, Southampton General Hospital, Tremona Rd, Southampton, SO16 6YD, UK).

COMMENT. Chorea, tics, and obsessive compulsive disorder (PANDAS) have been associated with streptococcal infections. Dyskinesias and associated psychiatric disorders following streptococcal infections are reported in 40 patients in the UK, and opsoclonus or myoclonus was present in 3 (Dale RC et al. Arch Dis Child 2004;89:604-610). Opsoclonusmyoclonus is parainfectious or a paraneoplastic disorder complicating neuroblastoma.

\section{NEUROLOGIC FINDINGS IN SYDENHAM'S CHOREA}

The relationship between cardiac and neurologic findings and long-term prognosis of 40 patients with Sydenham chorea were investigated at Istanbul University, Turkey. Patients were predominantly female $(70 \%)$, and mean age was $11.3+/-2.5$ years (range $4-16 \mathrm{yrs}$ ). Of 304 patients with rheumatic fever, $45(14.8 \%)$ had chorea during the first attack. Duration of chorea was $5.3+/-3.1$ months (range $1-12$ months). Chorea was mild in $30(75 \%)$, moderate 